\title{
Landscape Change in the Southern Piedmont: Challenges, Solutions, and Uncertainty Across Scales
}

\author{
$\underline{\text { Michael J. Conroy }}^{1}, \underline{\text { Craig R. Allen }}^{2}$, James T Peterson ${ }^{1}, \underline{\text { Lowell, Jr. Pritchard }}^{3}$, and Clinton T. Moore ${ }^{4}$
}

\begin{abstract}
The southern Piedmont of the southeastern United States epitomizes the complex and seemingly intractable problems and hard decisions that result from uncontrolled urban and suburban sprawl. Here we consider three recurrent themes in complicated problems involving complex systems: (1) scale dependencies and cross-scale, often nonlinear relationships; (2) resilience, in particular the potential for complex systems to move to alternate stable states with decreased ecological and/or economic value; and (3) uncertainty in the ability to understand and predict outcomes, perhaps particularly those that occur as a result of human impacts. We consider these issues in the context of landscape-level decision making, using as an example water resources and lotic systems in the Piedmont region of the southeastern United States.
\end{abstract}

\section{INTRODUCTION}

The southern Piedmont region of the United States is defined here as the $161,430-\mathrm{km}^{2}$ land area between the Appalachian mountains on the west and the Coastal Plain to the east and south (U.S. Department of Agriculture 1981). It extends from Virginia in the northeast to east-central Alabama in the southwest (Fig. 1). The region has a comparatively mild climate, with average annual temperatures of $14-18^{\circ} \mathrm{C}$ and annual precipitation of $115-140 \mathrm{~cm}$. Winters are generally mild, with light snowfall (U.S. Department of Agriculture 1981). Although groundwater supplies tend to be modest, abundant precipitation and perennial streams have historically provided reliable sources of water for agricultural, industrial, and municipal use.

The mild climate, gentle topography, and abundance of water for consumption, industry, and transportation assured that the region would experience rapid human population growth during the colonial and early national periods. During the 19th century, much of the "first forest" of the Piedmont was cleared for timber and for agriculture, and, by the time of the Civil War, the region was heavily settled and intensively farmed. Although much of the region was devastated by war, post-Reconstruction recovery resulted in continued population growth into the 20th century. A combination of factors including economic depression, the destruction of cotton crops by boll weevil infestation, and severe soil erosion led to the widespread abandonment of farmland from the 1930s through the 1950s. After the collapse of the sharecropper system and the reconfiguration of agriculture, many of the inhabitants migrated to racially segregated urban areas within the South and the northern United States (Cowdrey 1996). Subsequently, much of this formerly agricultural land was reforested, some in industrial holdings but more in private, nonindustrial ownership.

Since World War II, population growth in the states of the southern Piedmont, and particularly in the Piedmont itself, has been rapid, outpacing growth in the United States as a whole (Fig. 2). Thus, although this region has a shared developmental and cultural history, it is currently undergoing cultural, demographic, and environmental transitions that have profound implications for the future and for the sustainable development of the region. Human population growth is particularly rapid and continues to accelerate in urban and suburban areas and connecting corridors. Migration from other regions of the United States and international immigration have fueled much of this growth (Garreau 1991) and has dramatically changed the cultural and ethnic composition of many portions of the region. Growth is particularly rapid along certain urban and neo-urban centers, much of this in association with the interstate 
highway system, e.g., I-85, I-40, and I-75, and "developmental" highways (Fig. 3). By the 2000 census, $11 \times 10^{6}$ people lived in a "Piedmont Megalopolis" stretching from Alabama to North Carolina along the I-85 corridor. To the northeast, this megalopolis merges with an older Mid-Atlantic corridor extending from Richmond to Baltimore, which in turn merges with the even older and more densely developed northeast urban corridor (Tamman 2001).

Fig. 1. Southern Piedmont region of the United States.

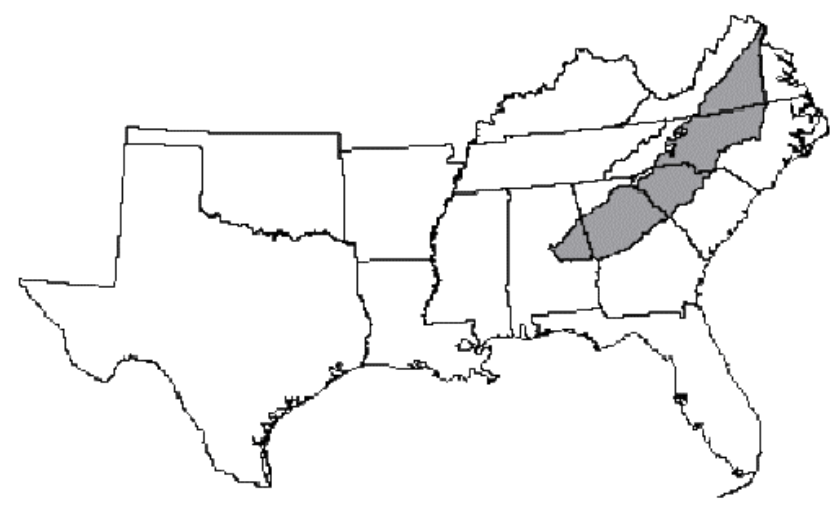

The cultural and political implications of the emergence of the "Sunbelt" were a matter of much debate in the 1970s (Larsen 1990), but the environmental implications were less noticeable and are still being discovered. Regional population growth, along with economic and other factors discussed below, has contributed to the conversion of rural, forested, and agricultural land uses and land covers to urban and suburban uses in many areas. The southern Piedmont is forecast to experience a greater loss of forested land than other regions of the South (Wear and Greis 2001). In addition, already high rates of forest fragmentation are expected to increase as human population growth accelerates in urban and interspersed suburban and rural communities (Wear and Greis 2001). As human population growth and developmental sprawl continue in this region, concomitant changes in ecosystem integrity and the production of ecological goods and services can be expected, including losses in water availability and quality, native habitats, and biological diversity; impacts on air quality; and conversion of forest lands to altered, largely urban, states. Responses to sprawl have their own environmental effects as more compact and intensive "infill" development leads to loss of urban forests, increased pressure on aging sewer systems, increased stormwater runoff into degrading stream systems, and an intensified heat-island effect. Together these developments have greatly stressed aquatic ecosystems through depletion of ground- and surface water sources, impacts on flow regimes, and point- and nonpoint-source contamination of water (Richter et al.1997, Warren et al. 2000).

Fig. 2. Rates of population growth in 10-yr intervals for the United States as a whole, the southeast from Alabama to Virginia, and the southern Piedmont.

Intercensus growth

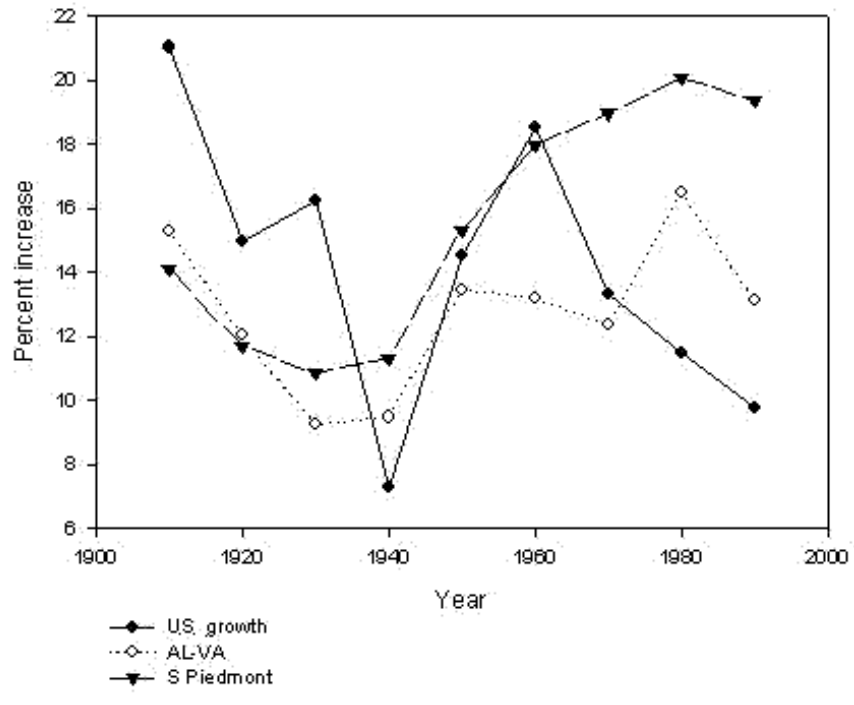

It seems apparent to many that the continuation of these environmental trends, if unabated, will eventually lead to a serious depletion of the "natural capital" (Costanza 1997, Daily and Ellison 2002) of the region, with the ensuing loss of biological diversity and ecosystem function and the human values that these provide. Policy makers may assert that these natural systems are robust to human impacts and can co-exist with projected patterns of human growth and development. Increasing development may diminish the level of nature's services, but this is often described as a (mere) tradeoff, as if the level or intensity of development incrementally alters natural systems, and as if an optimal combination of nature and development is possible to find. We suggest instead that the resilience of these systems decreases with increasing human impacts, defining resilience as the ability of ecosystems and landscapes to respond to disturbances in such a way as to remain in, or have the 
ability to return to, a given state. That is, the current integrated system, which consists of natural ecosystems tightly linked to human settlements and economic and social forces, may become increasingly vulnerable to perturbations from which it was previously able to recover. If sufficiently perturbed, the system may change to a less desirable state and thus reduce natural capital and services, human quality of life, and policy options. From this point of view, even gradual changes in the pressure exerted by humans on natural systems may result in sudden, discontinuous change from which recovery will be difficult, if not impossible. On the assumption that the future has value to society, this paper focuses on conceptual and technical issues related to the investigation of these alternative future landscapes. We examine how, and whether, current decisions may be directed so as to achieve more robust management strategies that incorporate concepts of ecosystem and landscape resilience.

Fig. 3. The I-85 transportation corridor in the southern Piedmont.

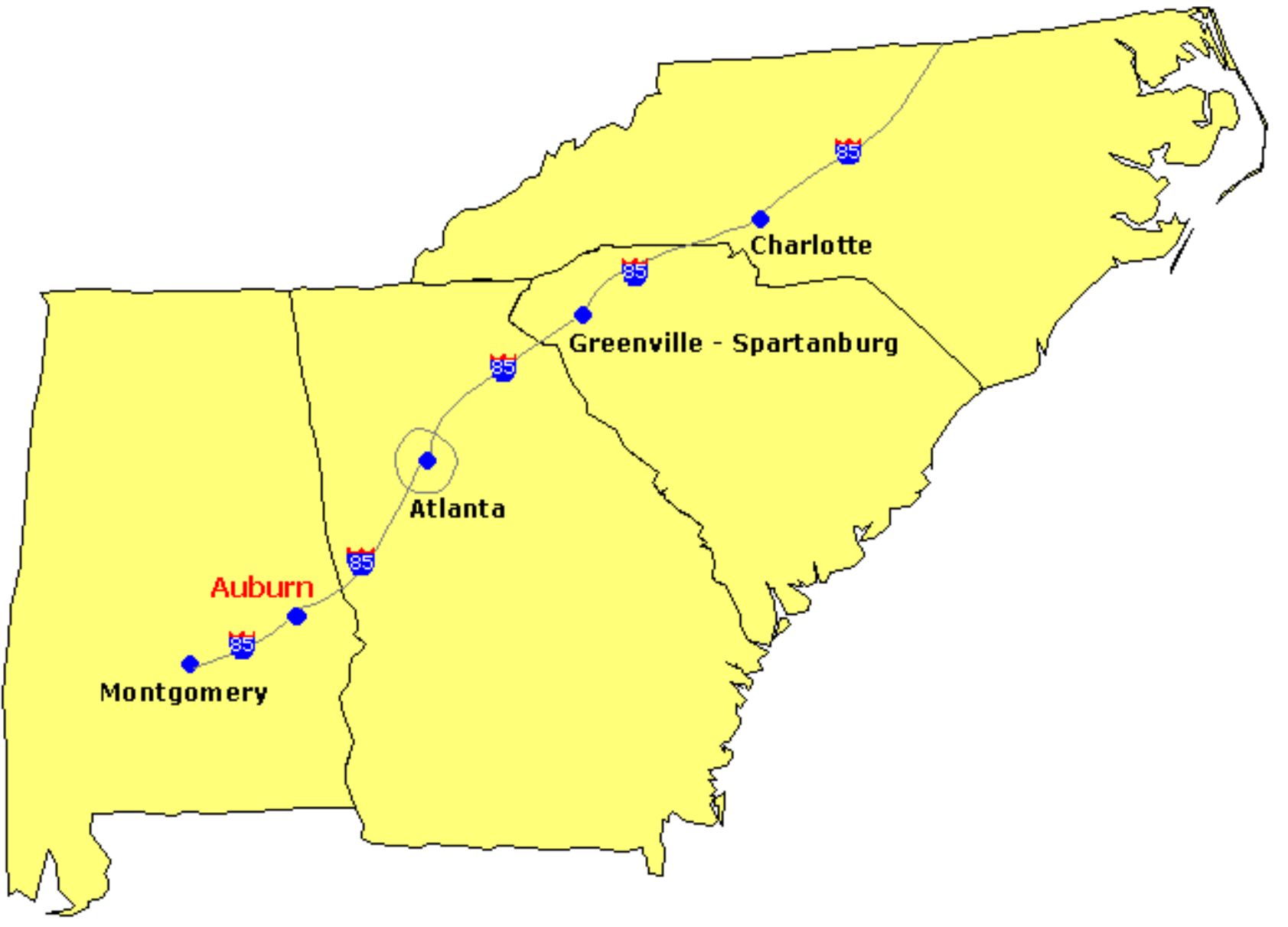

\section{CONCEPTUAL ISSUES}

\section{Decision making}

We begin by describing a general conceptual framework for decision making (e.g., Lindley 1985) that incorporates the essential elements of any naturalresource decision problem (Fig. 4). Generically, we assume that some aspect of the state of a natural resource system $\left(X_{0}\right)$ can be observed, and that a decision $(D)$ can be selected to achieve some value or utility $(u)$, which may in turn involve direct socioeconomic benefits, ecological services of direct or indirect value, esthetics, and other commodities or amenities. The system state following the decision $\left(X_{1}\right)$ may, but need not be, altered positively or negatively as a consequence of the decision (Fig. 4A). Furthermore, the utility of the decision may be affected not only by the immediate, e.g., short-term, economic benefits of the decision, but also by the state 
of the system following the decision (Fig. 4A). For example, a land management action may, in addition to producing immediate benefits, alter the landscape in such a manner as to either enhance or detract from those benefits (Fig. 4B). It will become clearer below why and how these future states should be valued in our decision- making process.

Fig. 4. Conceptual models of single-step decision making. In the various parts of this figure, $X$ represents the system state, $X_{0}$ an observed aspect of the system state, $D$ a decision, $X_{1}$ the system state following the decision, $u$ a value or utility, $*$ the output from a single model, ** the output from an alternative model, $t$ time, and $M$ a model describing the relationship between $X, D$, and $u$. This figure is discussed in some detail in the Decision making section.

A.

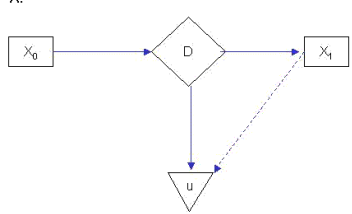

B.
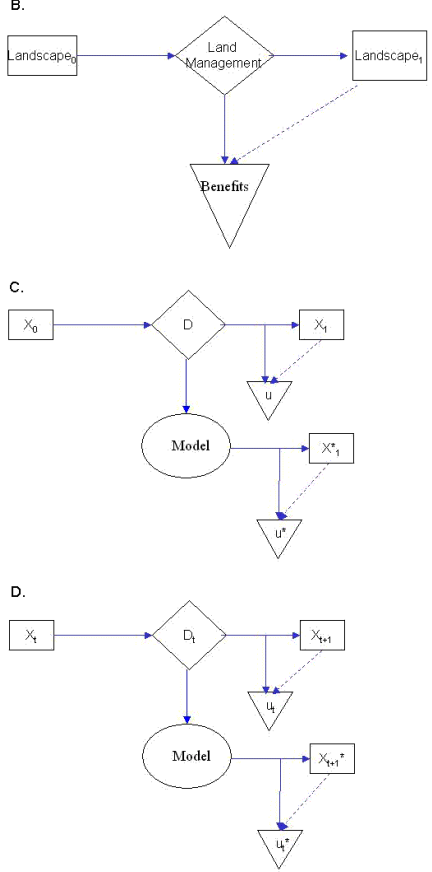

E.

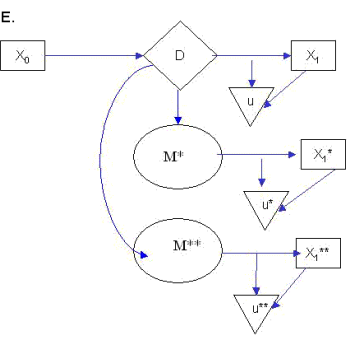

F.

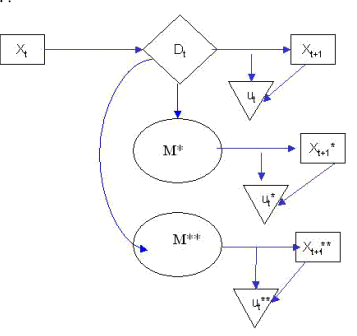


Although there is a presumed but unknown relationship between any given resource decision and future outcomes and benefits, in practice the relationship between $X, D$, and $u$ is captured by a model (Williams et al. 2002), which may but does not necessarily involve a mathematical representation of the utility expected from decision $D_{0}$ given state conditions $X_{0}$. The model generates predictions of these quantities, denoted by asterisks in Fig. $4 \mathrm{C}$ to distinguish them from actual outcomes.

Of course, in most cases, we are, or should be, dealing with objectives that are evaluated over a long time frame (see below) and with decisions that will change depending on system conditions, our knowledge of the system, and our vantage point with respect to the objectives. Hence, most land management decisions are dynamic in nature. There are several implications of dynamic decision making. First, because it will ordinarily be assumed that decisions at any time affect the future state of the system, we now need to explicitly take into account system dynamics; thus, the system state $X$ is now indexed by time $(t)$, as seen in Fig. 4D. Second, because current decisions may affect future system states, they may also affect our future opportunity to obtain value from the system. Assuming that the objective is long term, current decisions are therefore no longer independent of future decisions, and optimal policies fundamentally must take into account future opportunities. A third implication, which we will consider in more detail below, is that actions taken at earlier time points lead to predicted future system states that differ under differing model assumptions, which can then be compared to observed system states when these data become available. This introduces the possibility that learning may be integrated into the process of monitoring and making decisions.

Figures 4A-D illustrates the situation, unfortunately common, in which a single set of mathematical relationships and parameter values, i.e., a "model," is used to represent the relationship between $X, D$, and $u$. In general, it is prudent to consider at least one, and often several, feasible alternatives to the model structure, parameter values, or both, especially to the extent that (1) alternative models lead to different conclusions about the impacts and benefits of the management decision, and (2) at least some uncertainty exists as to model structure and/or parameter values. We represent this idea in Figs. 4E$\mathrm{F}$, in which an alternative model produces different state and utility values, now denoted by **, in comparison to those of the single model considered in Figs. 4A-D, which are marked with a single asterisk (*). Although we have used the device of discrete models to represent model uncertainty, we note that this notion of alternative models can in some cases be captured by specifying statistical distributions for parameter values. We return to the issue of uncertainty in decision making, and its components, in more detail below.

\section{Definition of objectives}

As suggested above, our premise is that certain future landscapes may become less valuable because their resilience has been either reduced or exceeded, causing the system to move to a less desirable state. In either case, policy options are limited. Without ceding the question, we leave to others (e.g., Czech 2000) the issue of whether projected rates of human population growth are either necessary or desirable from a socioeconomic point of view. Instead, we assume that growth will occur, and concern ourselves with the investigation of how, and whether, it may occur in a way that allows ecological systems to remain functional. We examine how, and whether, current land management and development decisions may be directed so as to achieve strategies that incorporate concepts of ecosystem and landscape resilience.

One challenge, then, is to develop a set of indicators for evaluating the natural capital and natural services that result from alternative policies. To be useful in an optimal policy framework, these indicators would have relative values, perhaps even economic values, and a model that explicitly describes the relationship between those values as an objective function. However, even outside an optimization framework, a rich set of indicators would still be useful in multipleattribute decision making. We suggest that a useful set of indicators should include the following attributes:

1. The incorporation of natural capital and nature's services, that is, those products and services that provide benefits to humans, even though they are often ignored in classic economic analyses (Costanza 1997, Daily and Ellison 2002). Examples include the provision of clean water and air and the ecological services that produce these, amenities provided by nature ranging from parks to ponds, and more traditionally valuable commodities such as trees for timber or pulpwood.

2. Sustainability. Indicators should describe the 
likelihood of maintaining desirable outcomes or of forestalling undesirable outcomes over an indefinitely long time horizon. This raises a tension, which we identify but do not resolve, with the practice of discounting future outcomes. It also raises scale issues, some of which are addressed below, because sustainability may permit periods of local or temporary collapse and renewal provided that the existence of the larger system is preserved. Thus, our notion of sustainability is not a static or immutable condition, but a robust ability of ecosystems to continue to perform vital functions.

3. Management or policy relevance. We are concerned here with outcomes that are at least potentially under the control of policy makers and stakeholders at the regional scale of the southern Piedmont or more locally. Certainly, uncontrollable driving forces and events are important, whether they are relatively unpredictable, such as hurricanes and technological innovation, or simply exogenous to the Piedmont region, such as El Niño Southern Oscillation (ENSO) events and trade negotiations. For a decision-making process to have meaning, at least some aspects of the objective must be under at least the partial control of the decision makers; we focus on those aspects. However, as seen below in the section on scale issues, understanding linked systems of people and nature as complex adaptive systems means that the mechanisms are often misunderstood or misidentified. Entertaining and nurturing multiple models may help to sort out these misunderstandings, because different models may describe the way controllability changes over time. We maintain that the efficacy of management is not constant, and that an understanding of ecosystem dynamics is necessary for deciding on the value and timing of interventions.

4. Measurability. To be useful to a decisionmaking process, decision outcomes must be described in a way that makes some of them more valuable than others. In general, decision policies then focus on the more valuable decisions. In some cases, a rank ordering of decision outcomes may be sufficient. However, it will generally be preferable to describe outcomes quantitatively, via an objective function or mathematical expression of value. A single objective function may never properly capture the conflicting goals of stakeholders, but postulating multiple objective functions may help policy makers to understand stakeholder interests and likely behavior and lead to more informed cooperation, the development of incentive programs, or properly targeted regulation. As seen above, objective functions must be tied to decision making and deal with the fact that some objectives accumulate across scales, whereas others emerge as scale-dependent properties (see below). A recurring criticism is the frequent reduction of value to economic value and the unwillingness or inability of stakeholders to frame their values in this way. However, decision making occurs in other domains than the market, and the process of quantifying outcomes is probably helpful in all of them (Pritchard et al. 2000). A more important point is that the values people attach to levels of ecosystem services are generally unknown even to the individuals holding them: they emerge and evolve as part of a process. This phenomenon is highly contingent on the forum, and the values formed in the marketplace may be different than those formed in the community (Pritchard and Sanderson 2002). Moreover, the stakeholders are changing constantly in terms of numbers, composition, preferences, and environmental expertise, all of which, we suggest, confounds simplistic efforts to reduce the complexity of decision making.

5. Predictability. A rational decision-making process implicitly involves a predictable connection between one or more decision alternatives and desired outcomes or objectives. This, in turn, implies a predictive model to establish a quantitative relationship between contemplated actions and an objective function. For problems such as the one at hand, the model will necessarily include a combination of factors. These factors range from some relatively well understood or quantified relationships, such as mapped locations of habitats and historical rates and patterns of human population growth, through less well understood predictive relationships that include animal population response to habitat change and forecasted patterns of human population growth, to purely stochastic 
unpredictable phenomena such as hurricanes, droughts, and other major catastrophes that can be described only in terms of probability models. Added to this complexity are the controllability issues mentioned above and the resilience and scale issues discussed below. In contrast, actual decision-making processes usually involve multiple objectives as well as a combination of identified and unidentified decision makers who interact at multiple scales, exercise varying degrees of coercive political power or manipulation on each other, and variously try to maximize utility, minimize regrets, maintain power, create uncertainty, postpone decisions, or avoid looking silly while arguing about the predictability of outcomes. Hence, most decisions may be ultimately irrational.

Fig. 5. A conceptual model of resilience and alternate stable states. The system initially is in the state on the left. (A) High resilience results in a low probability of transition to the alternate state on the right. (B) Loss of resilience results in a high probability of transition to the alternate state, which once attained $(\mathrm{C})$ is relatively stable because of its high resilience. As a result, there is only a low probability of returning to the first state.

A.

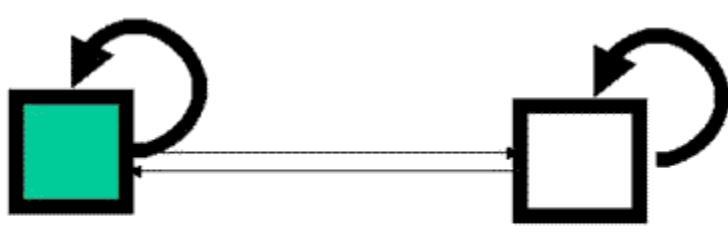

B.

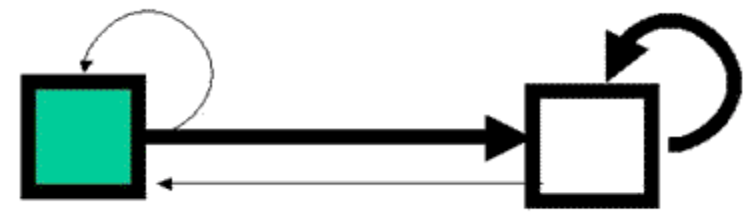

c.

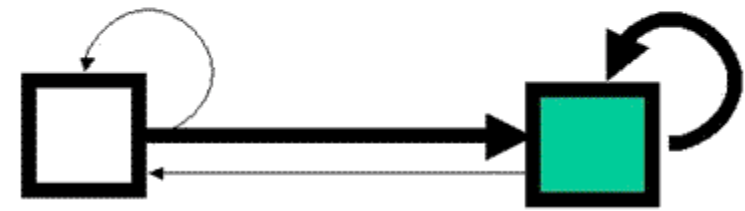

\section{RESILIENCE}

Ecological resilience (Holling 1973) is a measure of the amount of change or disruption that is required to transform a system from one that is maintained by one set of mutually reinforcing processes and structures with a stable but dynamic domain to one that is maintained by a different set of processes and structures, i.e., an alternate stable state (Fig. 5). A large amount of change or disruption is required to change the state of a system with high resilience, whereas a system with low resilience may change states following relatively minor disruption. In Fig. $5 \mathrm{~A}$, the system is at a stable dynamic equilibrium in an initial, e.g., desirable, state with high resilience. A change in some structuring force may decrease the resilience of the system, i.e., increase its vulnerability to disturbance. With reduced resilience, perturbation is more likely to result in transition to an alternate, e.g., lower value, state (Fig. 5B). In the figure, the alternate state also has high resilience, so that once this state is reached it may be difficult or impossible to revert to the original state (Fig. 5C). An example might be a forest undergoing a severe drought, which in itself is an ecosystem stressor but which also increases the vulnerability of the trees to a devastating insect outbreak. A second example might be slowly increased levels of fine fuels on the forest floor, which at some threshold dramatically increases the likelihood of fire spreading throughout the system.

The issue of resilience is particularly important when making decisions about the southern Piedmont because the failure to avoid alternate stable states that are undesirable, i.e., result in losses of ecological goods and services, represents a sort of policy trap. That is, by the time that it is clear that such a state has been reached, it may be extremely difficult or expensive to achieve an alternate state, and, if the range of policy options is sufficiently narrow, it may be impossible. Therefore, we would presumably want to place a high premium on avoiding stable undesirable states. To do so, however, may require predictive ability beyond the capacity of current data and models. This, in turn, signifies that the quantification of uncertainty in predictive models as described below should have high value, whether or not the uncertainty can be reduced (Gunderson and Pritchard 2002). In other words, if the existence of landscapes with multiple stable states is acknowledged, and uncertainty admitted, environmental policy and ecological management can still benefit from having a model that explains rather than predicts (see, for example, Peterson 2002). 
Fig. 6. A hierarchy of spatial scales: (A) coarse landscape scale, (B) local population/ watershed scale, and (C) fine, e.g., segment of stream, scale.

$\mathbf{A}$

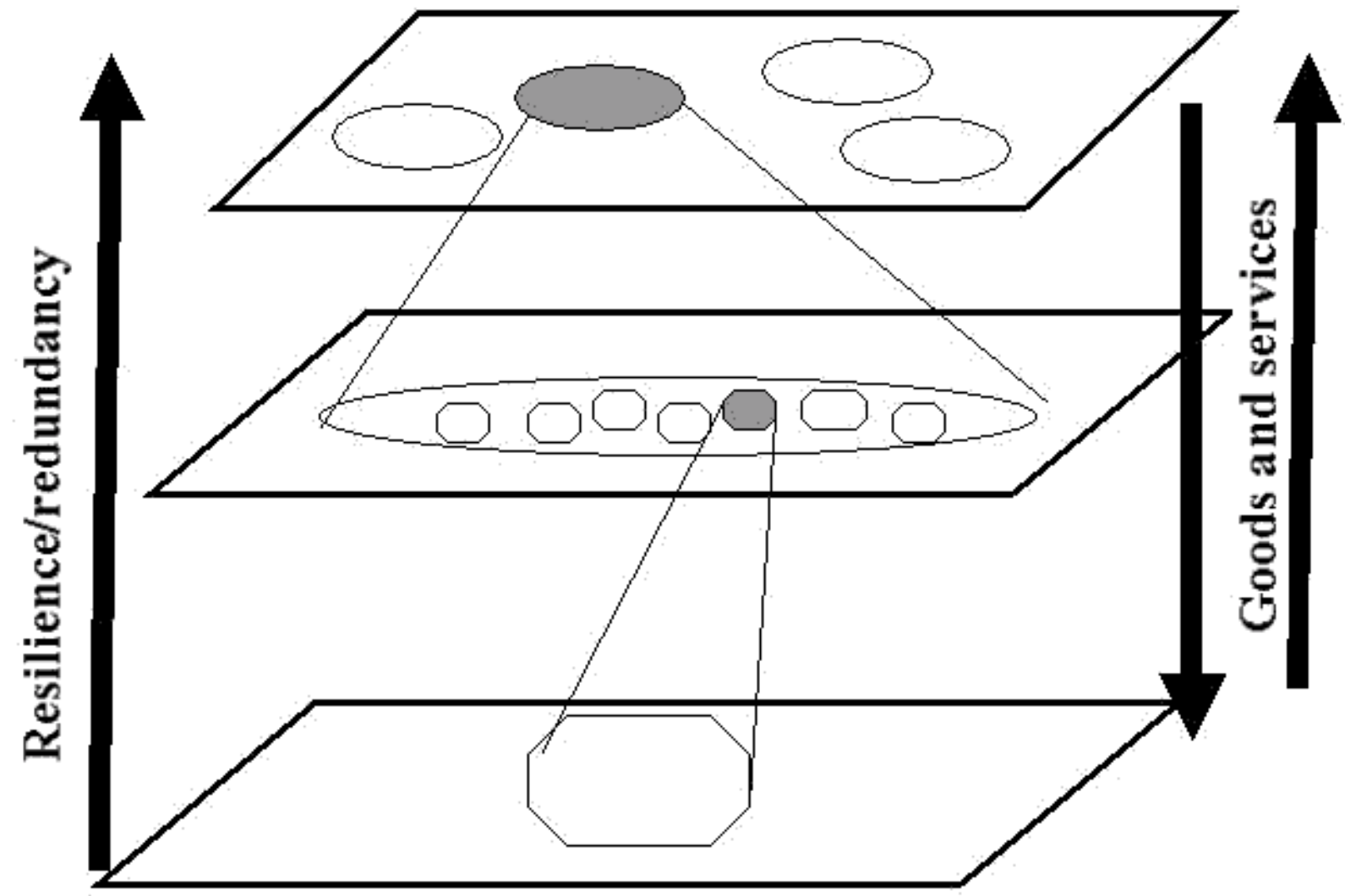

\section{SCALE OF ECOLOGICAL AND DECISION-MAKING PROCESSES}

The roles of spatial heterogeneity and spatial/temporal scale in ecological processes are increasingly understood as essential for a predictive understanding of these processes (Wiens 1989, Levin 1992, Pascual and Levin 1999). Scaling relationships fundamentally determine the ability to predict from one spatiotemporal scale to another, and thus whether actions that occur at one spatial scale can reliably be scaled up or down to predict processes at other scales (Fig. 6). Prediction becomes increasingly difficult when relationships are nonlinear and the variables of interest are emergent. The production of ecological goods and services and the generation of resilience do not occur at a single scale, nor are they spread continuously across scales. Resilience is generated in complex systems such as the southern Piedmont by a reinforcement of apparently redundant functions across scales and a partial overlap, or imbrication, of function within scales (Peterson et al. 1998). The loss of functions or services at one scale can be compensated for in the short term because, within a range of scales, there is some overlap among different functions and because, at different scales, the same function is likely to remain intact. However, resilience is decreased, and systems may collapse, when the system is perturbed at the scale that corresponds to the lost function. For example, the conversion of a forested landscape to an urban/suburban landscape would result in an increase in runoff and nonpointsource contamination in the aquatic systems and thus a loss in the value of an ecological service at the local and regional scales. Although the system might be resilient to such impacts given perturbation only at a local scale, e.g., organisms could migrate or recolonize from up- or downstream, resilience to large-scale perturbations may be much lower, e.g., a whole watershed affected by development (see, for example, 
Figs. 7A-B). In addition, the resulting alternate stable state, once attained, would have high resilience, meaning that it would be relatively difficult and costly to move to a preferred alternate state (Fig. 7C).

Fig. 7. The impact of spatial scale on resilience: (A) a system with both relatively high value and high resilience converts to (B) when a loss of system functionality on a landscape or regional scale reduces its resilience. Because of the low resilience of (B), there is considerable likelihood of transition to alternative stable state (C), which has low value but high resilience. Dark patches denote areas adversely influenced by human impacts.

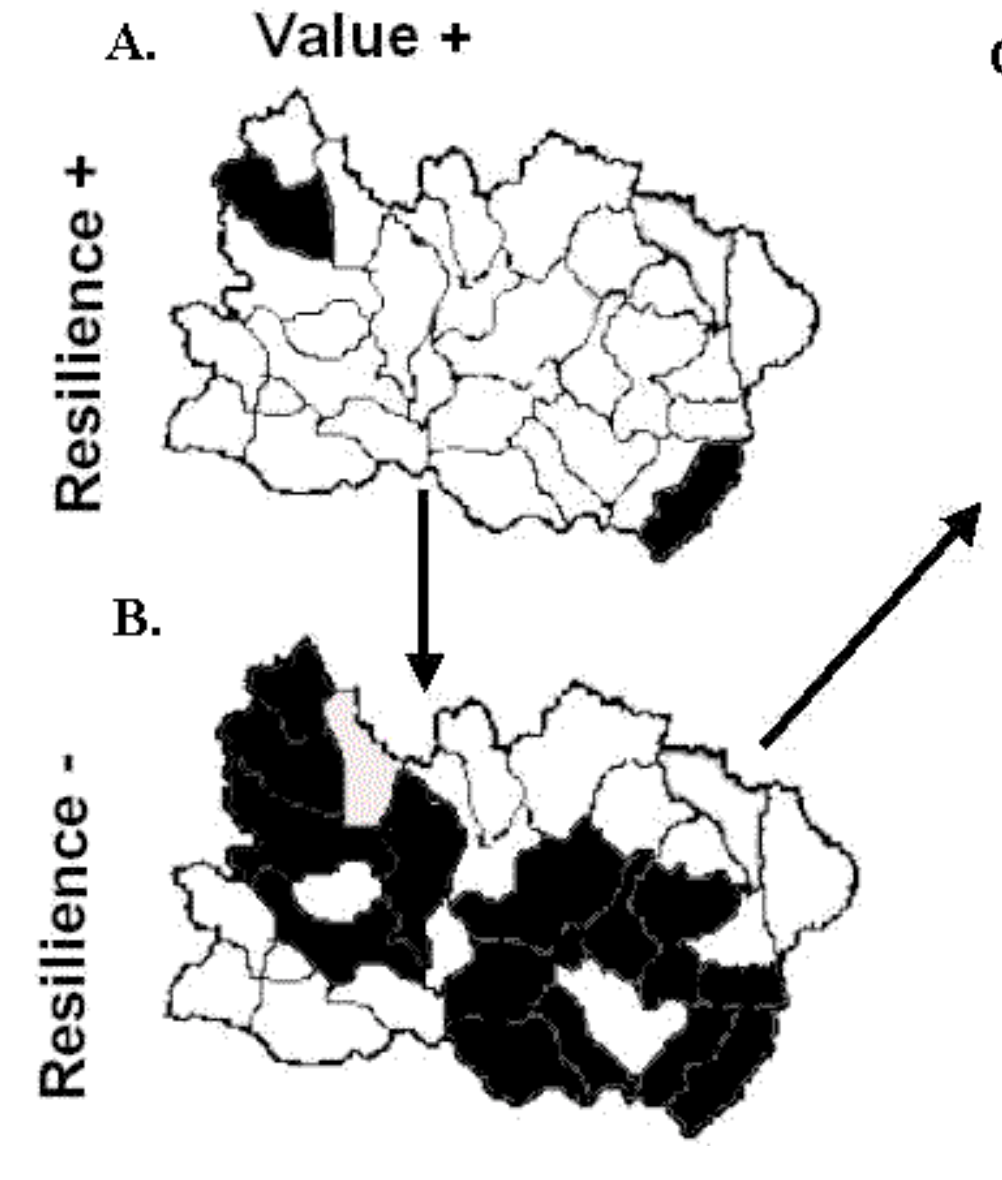

C. Value -

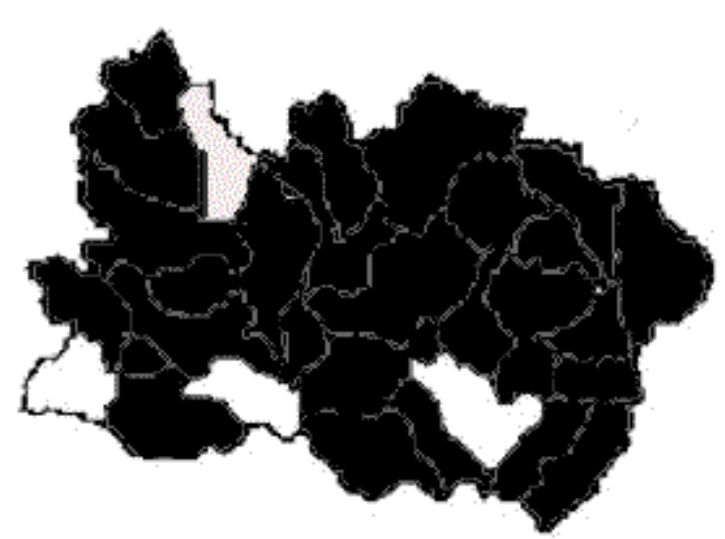

Multiple scales of decision making also complicate policies, predictions, and understanding. Any given ecological system on the landscape is likely to overlap multiple ownership and jurisdictional boundaries and fall under at least three levels of administrative control, particularly in the eastern part of the Piedmont, where ownership parcels tend to be small and interspersed. Land management decisions themselves occur at multiple spatial scales driven by the scale of influence of the decision maker. For example, decisions may be made by individual homeowners, by private owners of larger parcels, by firms owning huge tracts of land, or by county or state officials. The appropriate scale for decision making, defined as the scale of a desired ecological outcome, often does not correspond with the scale of political or economic decision making. Finally, resource objectives may conflict when objectives are defined on a finer or coarser spatial scale or with respect to more specific resource components. A clear example comes from water resources, where, even at a watershed or county level, upstream users have conflicts with other upstream users, e.g., recreation vs. power generation in reservoirs, where downstream users have conflicts with other downstream users, e.g., irrigation demand vs. instream flows, and where, at the larger scale of the 
river basin, upstream and downstream users obviously disagree about water use.

\section{Uncertainty}

We have emphasized that an ability to predict the consequences of alternative decisions for objective outcomes is fundamental to traditional decision making. However, it is clear that any forecasts or claims about "optimal" scenarios will be dependent upon critical assumptions. For example, assumptions about the "suitability" of alternative spatial arrangements of habitats may be highly dependent on the relative strength of local demographic processes such as reproduction and dispersal (Bevers and Flather 1999). Such relationships may be captured by mathematical and empirical models, but with high degrees of at least three types of uncertainty: (1) intrinsic or irreducible system uncertainty with both spatial and temporal components, caused by environmental and demographic variations; (2) statistical uncertainty because of the use of sample data to estimate model parameters; and (3) structural uncertainty stemming from the inability to determine which of several plausible alternative models best specifies the relationship between an objective function such as species conservation and system inputs and controls such as patterns of development, forest management, and conservation actions. All of these aspects of uncertainty must be considered in developing an understanding of the southern Piedmont region. We will place special emphasis on the third type of uncertainty because we believe that it has too often been neglected in predictive ecological modeling.

\section{CASE STUDY: ADAPTIVE DECISION MAKING TO MAINTAIN THE FUNCTIONALITY OF LOTIC ECOSYSTEMS IN THE SOUTHERN PIEDMONT}

The southern Piedmont is undergoing rapid transition, with projected increases in human population density and rates of land use conversion. Land uses are changing from a present mixture of light residential and industrial, agricultural, and lightly managed forest systems to a heavily developed and urbanized landscape and more intensively managed forest systems. As noted above, these changes have implications for many components of the ecological systems in the region. Here we focus on lotic ecosystems, i.e., streams and rivers, as (1) reflective of broad conditions of ecological functionality, (2) operating at various spatial scales, and (3) potentially responsive to both very localized, fine-scale perturbations as well as phenomena on a broader scale. Piedmont lotic ecosystems thus serve well to illustrate our three major conceptual themes: scale, resilience, and adaptive decision making. We recognize that the lotic ecosystems of the region are intricately and inextricably linked to the terrestrial ecosystems and consider them in isolation only to provide a clearer example. We could have focused on any number of other equally interesting ecological subsystems, including, for example, changes in populations of breeding birds or alterations in forest resource systems, all of which would serve our illustrative purpose just as well.

Although the importance of scale and resilience are by now well known to ecologists, we believe that the implications of these concepts are unlikely to be appreciated by decision makers, who frequently operate at a local scale and, among multiple decision makers, with diverse objectives. We illustrate a decision-making approach by first considering a bottom- up hierarchical model of ecosystem response to local conditions. At each level or spatial scale in the hierarchy, responses are constrained by upper-level or broader-scale conditions and phenomena, although, under certain conditions, lower levels of the hierarchy may at least temporarily control system dynamics. We show how a conservation objective can be formulated in terms of measured or predicted system states, fulfilling several of the criteria specified earlier, for instance, taking into account resilience. We then suggest how multiple-scale decision-making processes can be evaluated using this objective function. We explicitly incorporate different types of uncertainty, including uncertainty about biological processes, into a more-or-less traditional optimization framework and propose some alternative computational approaches for obtaining optimal policies in the face of this uncertainty. Finally, we describe how an adaptive approach of combining management, prediction, and updating can reduce uncertainty over time, leading to improved decision making.

\section{Background}

The issue of water management in the Piedmont region can be considered at multiple spatial scales. At 
a broad scale, the rapidly developing southern Piedmont region contains the headwaters for seven major Atlantic Slope and two Gulf Coast drainages (Fig. 8). The unique geologic history and climate of the region have fostered the generation of some of the highest levels of aquatic faunal diversity and endemism recorded in temperate freshwaters. At least 200 native species of freshwater fishes occur in the southern Piedmont (Warren et al. 2000), as well as a relatively diverse mollusc fauna (Bogan et al. 1995, Burkhead et al. 1995, Neves et al. 1997). Many of these species are declining or otherwise considered at risk. For example, 51 species of endemic freshwater fishes (Warren et al. 2000) and approximately onequarter of the mollusks (Neves et al. 1997) in the region are classified as threatened, endangered, or vulnerable to extirpation.

Fig. 8. Atlantic and Gulf slope watersheds.

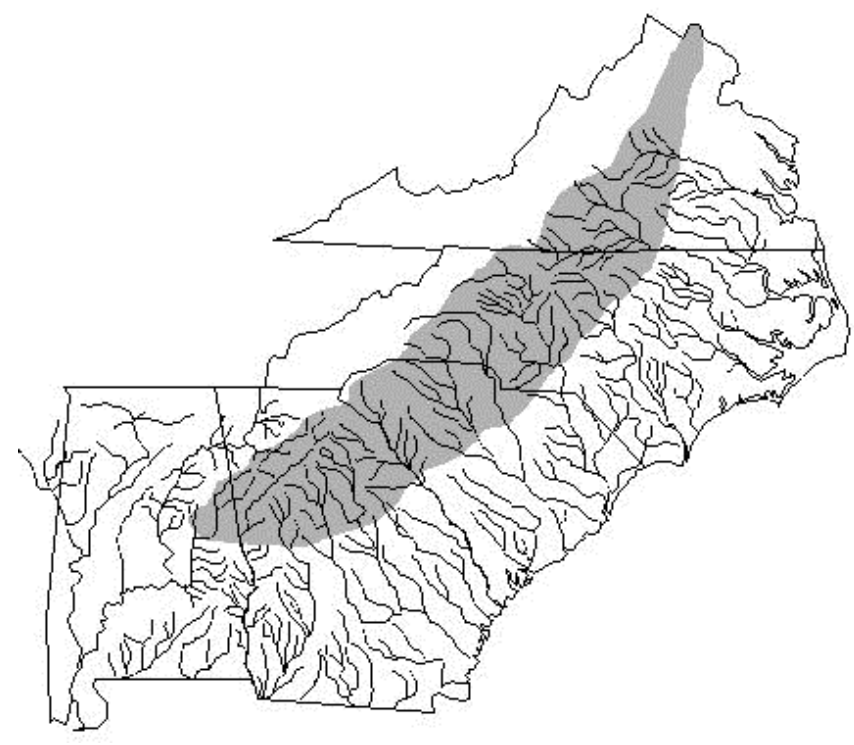

Degradation at the regional scale can largely be attributed to the accumulation of many local or finerscale actions. Thus, declines in endemic fish occurred primarily because of the habitat alteration and degradation resulting from forest conversion to intensive agriculture, urban growth, and river impoundment. Among these, stream flow regulation and water development have been identified as the foremost problems threatening aquatic biota in the southeastern United States (Richter et al. 1997). For example, dams and reservoirs impound nearly all the mainstem rivers draining the southern Piedmont, and more than 50 water supply reservoirs are in planning phases for construction or have been approved through the U.S. Army Corp of Engineers 404 permitting process described below but have not yet been constructed. Much of the southern Piedmont is currently undergoing an exceptional multiyear drought, which has led to attempts to quickly increase water resources by creating reservoirs. Further increases in land development expected in the southern Piedmont will likely place greater demands on the remaining unexploited water resources in the near future. Additionally, water resource development in the Piedmont has led to inter-regional and interstate conflicts with downstream and upstream users (e.g., Meador 1996).

Streamflow regulation and water development can have profound effects on the structure, function, and resilience of lotic ecosystems and thus on ecological resilience. The most obvious of these occur when streams are impounded and the state of the affected stream section is changed from lotic to lentic. These altered systems no longer support obligate lotic fauna and, consequently, over time the aquatic communities become dominated by lentic species (e.g., Zhong and Power 1996). Stream impoundment also alters many of the functions of the previously lotic system, such as sediment and organic matter transport (Ligon et al. 1995), which affects the structure of unimpounded downstream areas. At larger scales, the cumulative effects of streamflow regulation and water development may significantly affect the resilience of lotic ecosystems. For example, increased fragmentation caused by reservoir construction and land use change would likely lower the resilience of the system to natural and man-made disturbances by eliminating connectivity with adjacent populations and potential colonization sources. These disturbances include droughts, artificial alterations in streamflow, nonpoint-source pollution, chemical and sewer system spills, pulses in sediment load from storms, and temperature fluctuations.

Increased urbanization is likely to increase the variability, frequency, and intensity of these disturbances. Vegetation removal or change, road construction, and increases in the amount of impervious surfaces associated with urbanization affect the drainage, runoff, infiltration, sedimentation, and hydrology of lotic systems (Grover and Harrington 1966, Morisawa 1985), resulting in increased flood volumes and total runoff with shorter flood duration 
(Grover and Harrington 1966, Gordon et al. 1992). Disconnected lotic systems are likely to be more vulnerable to such disturbances. The interposed lentic states obviously have high resilience in a hydrological sense, because it would be impossible for an impounded reach to revert to its original lotic state as long as water-control structures remain, and even the removal of these structures may not result in a change in system state back to the original (Pejchar and Warner 2001). Because local and large-scale or cumulative alterations created by streamflow regulation and water development activities may be irreversible in the foreseeable future, decision makers should consider both when evaluating alternative management scenarios. The ecological resilience of artificially created lentic systems is a separate issue, because the new artificial ecosystems experience novel stressors and disturbances such as sudden drawdowns, clearing of shores for construction, etc.

Currently, the construction of all water-regulation structures such as dams requires a permit administered by the U.S. Environmental Protection Agency (EPA) and the Army Corps of Engineers (ACOE) under Section 404 of the Clean Water Act. When structures are proposed in areas known to contain threatened or endangered species, the U.S. Fish and Wildlife Service also participates in the review and permitting process. Permits may impose conditions on the construction and operation of structures with regard to the chemical, biological, and physical properties of water, including water quantity and quality. Unfortunately, these permits are generally evaluated and issued on an individual basis, with no regard for potential cumulative impacts. Below we outline an alternative landscape-level approach to water resource management.

\section{Modeling of landscape decisions}

The extent to which the function and resilience of an aquatic system is maintained under various landscape scenarios may be examined by either of two basic approaches. The first, the "simulation approach," would treat a species conservation "goal" simply as a passive output predicted under various water development scenarios, given various assumed model structures and estimated parameter values. The second or "optimal control" approach treats function/resilience explicitly as an objective, possibly in competition with other objectives, and seeks to actively find an "optimal strategy" corresponding to a desired numerical outcome. Both approaches fundamentally depend on underlying assumptions of system dynamics, which are subject to uncertainty. The decision model can be used to predict the impact of various natural resource policies on loss of function/resilience for various stream types in the Piedmont region. The four types included in the model are (1) small headwater streams; (2) small streams emptying into larger mainstem streams, also referred to as small off-channel streams; (3) large mainstem streams; and (4) impounded streams, i.e., reservoirs. Policies can be developed for each stream type using simulation and optimization techniques. Small headwater streams, small offchannel streams, and large mainstem streams could be simulated via a Markov process (Williams et al. 2002) to predict outcomes under alternative water development scenarios. The impounded stream category would be an absorbing state for this analysis. For example, three scenarios for regional water development could be considered:

1. the development of a few large, regional reservoirs;

2. the use of several small, reservoirs located on headwater streams; and

3. the development of several small, off-channel reservoirs.

Formulating and evaluating water development policies will require the creation of a spatial optimization model that explicitly treats the way in which the pattern and scale of impoundments determines the resilience of the overall system to a range of natural and man-made disturbances. Each of the scenarios includes reservoirs that have their own local effects on species assemblage, diversity, hydrology, water chemistry, and ecosystem function. However, the differences in overall configuration will, we believe, lead to different vulnerabilities to disturbance. Our model allows spatial goals and constraints to be applied to an area that includes the interdependency between streams, rather than allowing each stream to behave independently. Policies would be presumed to include flow standards and land use restrictions that require minimal standards for stream and reservoir buffers. Additional policies could consider alterative water development policies, such as water withdrawal from free-flowing streams and interbasin water transfer. In either case, we do not assume that standard policies would adequately take into account either the resilience or the sustainability of these systems. Rather, for each scenario, the 
outcomes of interest, i.e., the outcomes to be evaluated in optimal policy formulation, are not only the expected values and variability of ecosystem goods and services, but also their resilience to perturbation, which deals directly with issues of sustainability as discussed above.

Fig. 9. Hypothetical relationship between size of a lotic metapopulation and degree of river impoundment: (A) linear, (B) threshold, and (C) hierarchical model.

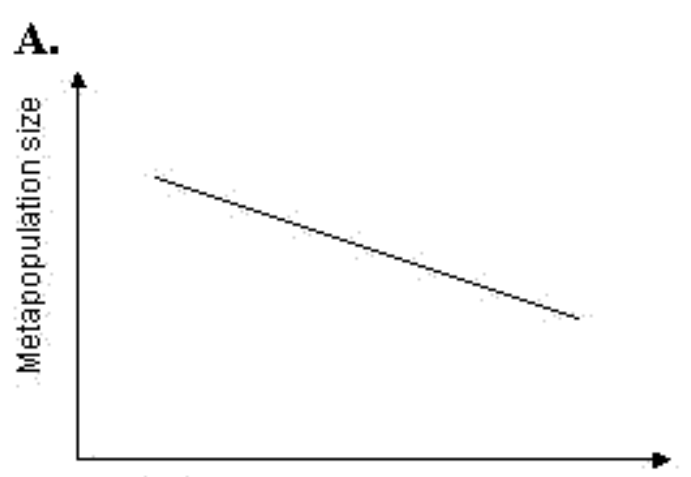

Total length of impounded streams
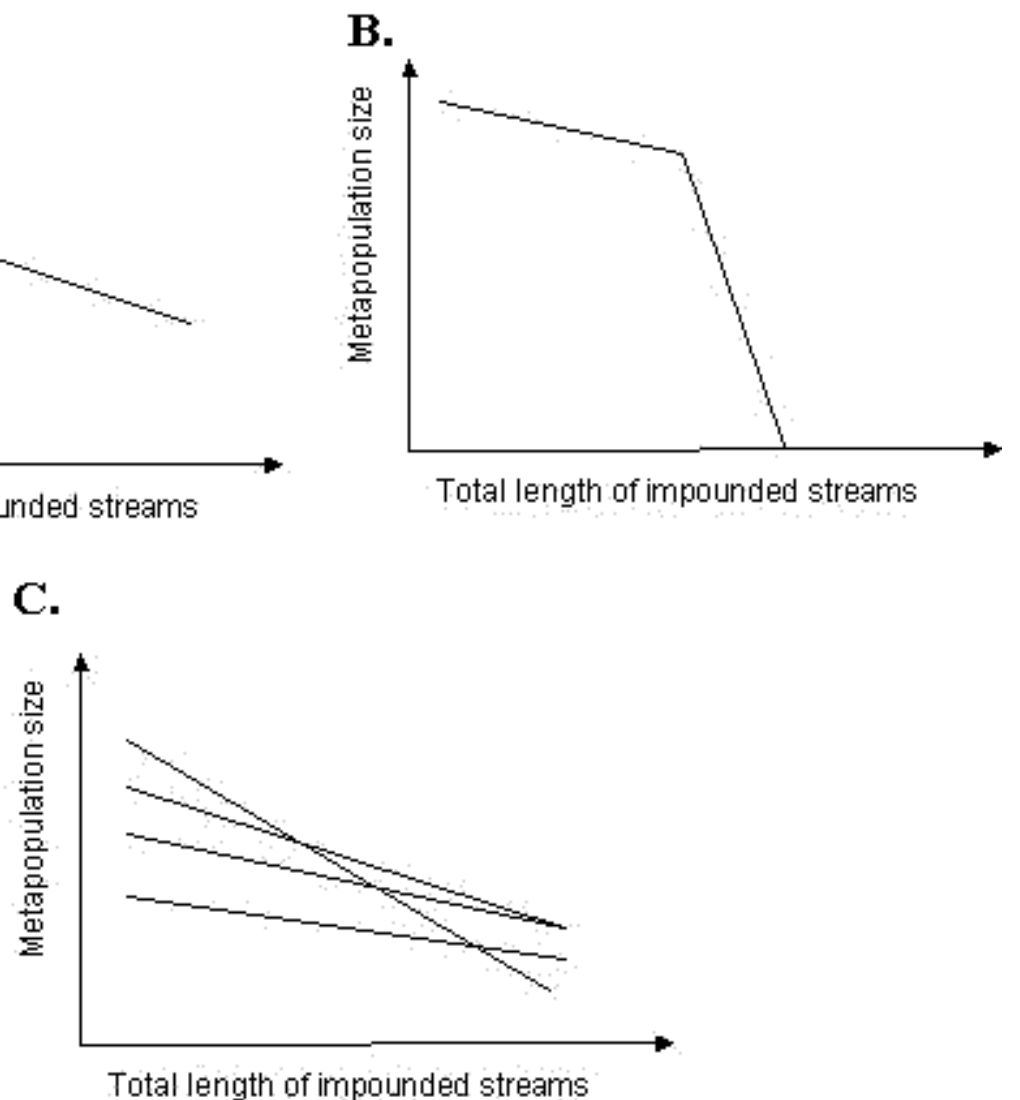

\section{Dealing with scale}

As discussed earlier, the effect of system changes may scale up in some additive or linear manner, whereas some responses may be scale-dependent and nonlinear. For example, the size of a lotic metapopulation could decrease in some linear fashion with increased river impoundment (Fig. 9A). However, in certain instances, as seen in Fig. 9B, increased river impoundment beyond some critical threshold may result in the extirpation of the metapopulation due to Allee or other effects (Keitt et al. 2001). Thus, one means of incorporating scale would be to develop alternative models. Another possibility is to develop nested, multiscale models, e.g., hierarchical models, in which the response at one scale is conditionally dependent on the response(s) at larger spatial scales (Fig. 9C).

\section{Adaptive feedback and learning}

All of the models discussed above, when coupled with the decision-making model, would allow both for forecasts under alternate water development scenarios and for the selection of optimal scenarios to meet specific conservation or other objectives. However, as discussed above, critical assumptions will condition claims for optimality because of the three kinds of 
uncertainty: intrinsic or irreducible, statistical, and structural. The effects of structural uncertainty on decision making can be explicitly considered by postulating "feasible alternative" models. Each model describes a hypothetical relationship among inputs, model states, and outputs; in particular, we seek alternative models that lead to different conclusions about the impacts of given land policies or management actions on our objective. In this way we hope to correctly portray the uncertainty in predictions of actual outcomes and to design management policies that would make it possible to learn about the system. The traditional approach, which is to adopt the model that a priori seems most likely and use it to generate a single "optimal" management recommendation, is rejected in favor of an adaptive approach (Walters 1986, 1997) that treats policies as experiments.

Fig. 10. Dynamic decision making under uncertainty. Sequential decisions $\left(D_{t}\right)$ are made subject to observations on the resource system state $\left(X_{t}\right)$ and information $\left(\right.$ Info $\left.o_{t}\right)$. Subsequent comparisons of realized system states $\left(X_{t+1}\right)$ to predictions under alternative models $\left(X_{t+1}^{*}\right.$ and $\left.X^{* *}{ }_{t+1}\right)$ are used with Bayes' Theorem to update model belief (Info $\left.o_{t+1}\right)$ for use in next round of decision making $\left(D_{t+1}\right) . M$ stands for model, and $u$ for value or utility.

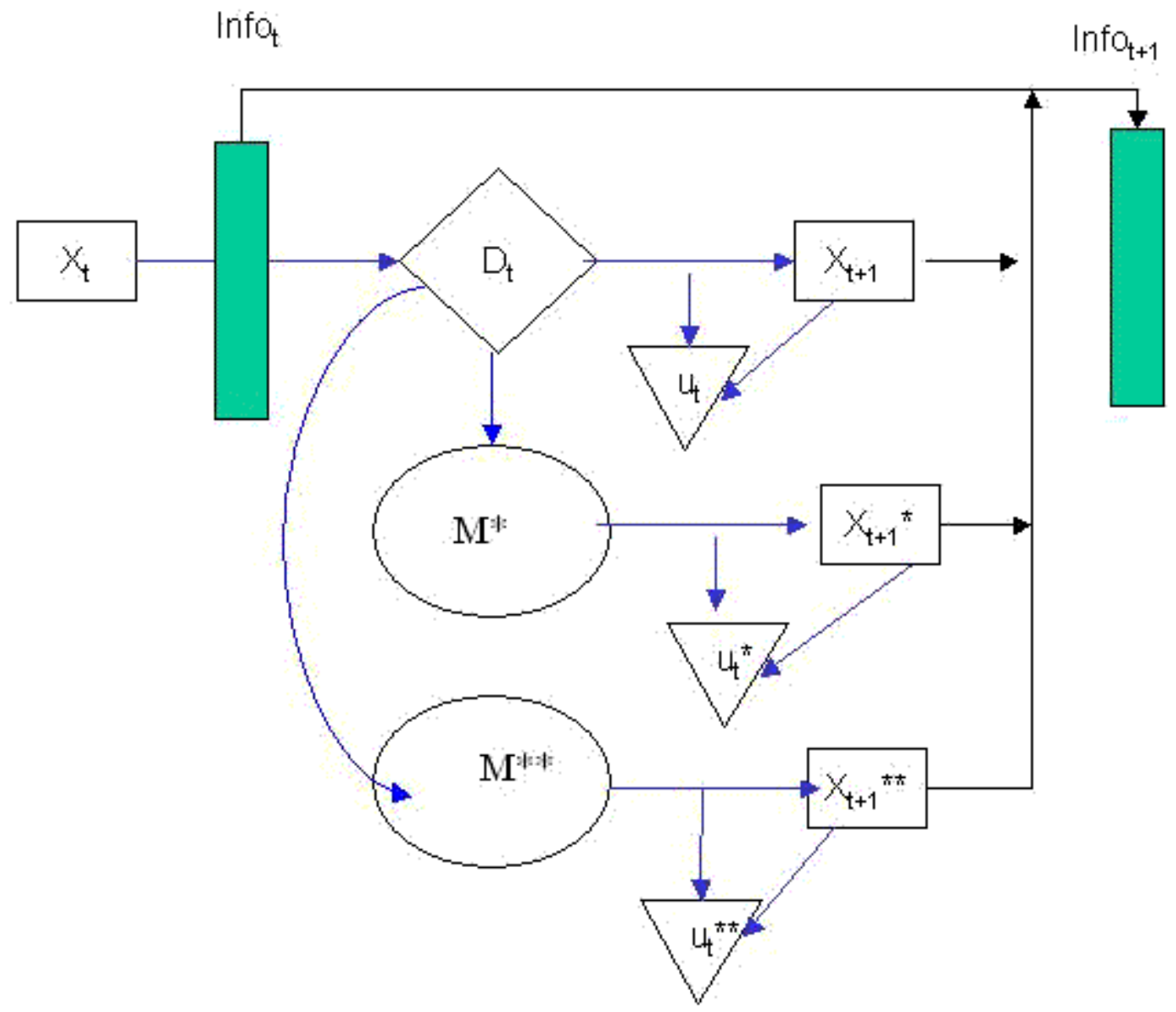

In fact, as seen in Fig. 10, adaptive management need not involve a loss of objective utility in favor of learning, but rather can involve the simultaneous striving for optimal system return with information feedback along the way (Williams et al. 2002). This approach should avoid the problems inherent in approaches that seek to stabilize the delivery of ecological goods and services at maximum sustainable yield or some other static target but also fail to exploit learning opportunities. In addition, such static 
approaches often alter the previous disturbance regime of the system, invalidating the model on which they are based and leading to a higher likelihood of ecological surprise (Holling and Meffe 1996, Gunderson and Holling 2001). In general, an adaptive decision-making and monitoring scheme (Williams et al. 2002) would entail several components, including:

1. assessment of the current state of the resource system. This includes the "information state" as measured by prior relative belief among alternative system models;

2. prediction of the expected impact of each action among the set of feasible alternative actions or decisions, taking into account environmental, demographic, structural, statistical, and other sources of uncertainty, and selecting as the best action the one that leads to the greatest expected gain, or least expected loss, in system return;

3. collection of monitoring data to assess the new current system state and compute the statistical likelihood under each alternative model, either after the action is taken if it was implemented landscape-wide, or concurrently if it was implemented on some spatial units but not others. This information would be used together with the prior model weights to compute a new posterior information state; and

4. repetition of steps 1-3 with the posterior information state as the new prior belief.

The above description may be characterized as "passive adaptive management," in that learning is a "by-product" of optimal decision making. That is, no deliberate attempt is made to gain information as part of the decision-making process. "Active adaptive management" occurs when decisions are made partly in anticipation of learning to reduce structural uncertainty and derive a greater long-term benefit (Williams et al. 2002). Either approach should be superior to "nonadaptive" decision making, in which either system uncertainty is ignored or learning, if it occurs, is not formally incorporated into decision making.

Our decision model, if implemented, would offer several improvements over current water management policy. First, both the implications of local decisions and the value of the ecological goods and services provided by functioning lotic ecosystems are considered over appropriately broad spatiotemporal scales. Second, important scale and resilience relationships and uncertainties in these and other functional relationships are explicitly accounted for in decision making. Third, adaptive management offers a means of pursuing water management policies that, given current understanding, appear to lead to the best objective value. Comparison of predicted to observed outcomes under alternative models of system response provides a means for improving understanding and decision making through time.

\section{SUMMARY}

In this paper we consider three themes that are common to complex ecological problems: (1) scale dependencies and cross-scale relationships among ecological processes; (2) resilience in ecological systems, in particular the tendency of systems to move toward alternate stable states as a result of perturbation; and (3) uncertainty in the ability to understand and predict ecological processes, particularly those that occur as a result of human impacts.

We consider these issues in the context of landscapelevel decision making, using as an example water resources and lotic systems in the Piedmont region of the southeastern United States. To proceed with the evaluation of alternative policies, it is first necessary to define objectives. These in turn require the appropriate valuation of ecosystem services, under the premise that some landscape scenarios, particularly those that are resilient and ecologically functional, are more valuable than others that are also highly resilient but ecologically dysfunctional. Also, to embody notions of sustainability, an appropriately long-term time frame must be defined over which ecosystem goods and services are to be valued. Decision makers and stakeholders must be identified and incorporated into a decision-making process; this becomes problematic because of the multijurisdictional nature of virtually any landscape-level decision process.

The three themes of ecological complexity, i.e., scale, resilience, and uncertainty, interact with the decisionmaking process in numerous ways. For example, scaling relationships and ecological resilience may buffer the influence of top-down policies. Likewise, both the disaggregated nature of local decisions and possible discontinuities in response because of the loss of resilience may lead to unpredictable cumulative 
impacts and "policy traps." Finally, uncertainty must be explicitly and properly dealt with in any decisionmaking process. The role of adaptive feedback of information is critical to both the identification of system state and trajectory, which is necessary for determining if objectives are being met, and the collection of data about, and hence the reduction of, process uncertainty.

Responses to this article can be read online at: http://www.consecol.org/vol8/iss2/art3/responses/index.html

\section{Acknowledgments:}

We thank the editor and three anonymous reviewers for useful comments on previous versions. The Georgia Cooperative Fish and Wildlife Research Unit is jointly sponsored by the U.S. Geological Survey (USGS), the University of Georgia, the Georgia Department of Natural Resources, and the Wildlife Management Institute. The South Carolina Cooperative Fish and Wildlife Research Unit is jointly sponsored by USGS, Clemson University, the South Carolina Department of Natural Resources, and the Wildlife Management Institute.

\section{LITERATURE CITED}

Bevers, M., and C. H. Flather. 1999. The distribution and abundance of populations limited at multiple spatial scales. Journal of Animal Ecology 68:976- 987.

Bogan, A. E., J. M. Pierson, and P. Hartfield. 1995. Decline in the freshwater gastropod fauna in the Mobile Bay basin. Pages 249-252 in E. T. LaRoe, G. S. Farris, C. E. Puckett, P. D. Doran, and M. J. Mac, editors. Our living resources: a report to the nation on the distribution, abundance, and health of U.S. plants, animals, and ecosystems. U.S. Department of the Interior, National Biological Service, Washington, D.C., USA.

Burkhead, N. M., S. J. Walsh, B. J. Freeman, and J. D. Williams. 1997. Status and restoration of the Etowah River, an imperiled southern Appalachian ecosystem. Pages 375444 in G. W. Benz and D. E. Collins, editors. Aquatic fauna in peril: the southeastern perspective. Special Publication, Number 1. Southeast Aquatic Research Institute, Chattanooga, Tennessee, USA.

Costanza, R., editor. 1997. An introduction to ecological economics. CRC Press, Boca Raton, Florida, USA.

Cowdrey, A. E. 1996. This land, this South: an environmental history. Revised edition. University Press of Kentucky, Lexington, Kentucky, USA.

Czech, B. 2000. Shoveling fuel for a runaway train: errant economists, shameful spenders, and a plan to stop them all. University of California Press, Berkeley, California, USA.

Daily, G. C., and K. Ellison. 2002. The new economy of nature. Island Press, Washington, D.C., USA.

Garreau, J. 1991. Edge city: life on the new frontier. Doubleday, New York, New York, USA.

Gordon, N. D., T. A. McMahon, and B. L. Finlayson. 1992. Stream hydrology: an introduction for ecologists. Wiley, New York, New York, USA.

Grover, N. C., and A. W. Harrington. 1966. Stream flow measurements, records and their uses. Dover Publications, New York, New York, USA.

Gunderson, L. H., and C. S. Holling. 2001. Panarchy: understanding transformations in human and natural systems. Island Press, Washington, D.C., USA.

Gunderson, L. H., and L. Pritchard, Jr., editors. 2002. Resilience and the behavior of large-scale ecosystems. Island Press, Washington, D.C., USA.

Holling, C. S. 1973. Resilience and stability of ecological systems. Annual Review of Ecology and Systematics 4:1-23.

Holling, C. S., and G. K. Meffe. 1996. Command and control and the pathology of natural resource management. Conservation Biology 10:328-337.

Keitt, T. H., M. A. Lewis, and R. D. Holt. 2001. Allee effects, invasion pinning, and species' borders. American Naturalist 157:203-216.

Larsen, L. H. 1990. The urban south: a history. University of Kentucky Press, Lexington, Kentucky, USA.

Levin, S. A. 1992. The problem of pattern and scale in ecology. Ecology 73:1943-1967.

Ligon, F. K., W. E. Dietrich, and W. J. Trush. 1995. Downstream ecological effects of dams: a geomorphic perspective. Bioscience 45:183-192.

Lindley, D. V. 1985. Making decisions. Wiley, New York, New York, USA.

Meador, M. R. 1996. Water transfer projects and the role of 
fisheries biologists. Fisheries 21(9):18-23.

Morisawa, M. E. 1985. Rivers: form and process. Geomorphology Texts, Number 7. Longman, London, UK.

Neves, R. J., A. E. Bogan, J. D. Williams, S. A. Ahlstedt, and P. W. Hartfield. 1997. Status of aquatic mollusks in the southeastern United States: a downward spiral of diversity. Pages 43-85 in G. W. Benz and D. E. Collins, editors. Aquatic fauna in peril: the southeastern perspective. Special Publication, Number 1. Southeast Aquatic Research Institute, Chattanooga, Tennessee, USA.

Pascual, M., and S. A. Levin. 1999. From individuals to population densities: searching for the intermediate scale of nontrivial determinism. Ecology 80:2225-2236.

Pejchar, L., and K. Warner. 2001. A river might run through it again: criteria for consideration of dam removal and interim lessons from California. Environmental Management 28:561-575.

Peterson, G. D. 2002. Forest dynamics in the southeastern United States: managing multiple stable states. Pages 227246 in L. H. Gunderson and L. Pritchard, Jr., editors. Resilience and the behavior of large-scale systems. Island Press, Washington, D.C., USA.

Peterson, G. D., C. R. Allen, and C. S. Holling. 1998. Ecological resilience, biodiversity, and scale. Ecosystems 1:6-18.

Pritchard, L., Jr., C. Folke, and L. H. Gunderson. 2000. Valuation of ecosystem services in institutional context. Ecosystems 3:36-40.

Pritchard, L., Jr., and S. E. Sanderson. 2002. The dynamics of political discourse in seeking sustainability. Pages 147-169 in L. H. Gunderson and C. S. Holling, editors. Panarchy: understanding transformations in human and natural systems. Island Press, Washington, D.C., USA.

Richter, B. D., D. P. Braun, M. A. Mendelson, and L. L. Master. 1997. Threats to imperiled freshwater fauna. Conservation Biology 11:1081-1093.

Tamman, M. 2001. Charlantingham: welcome to the big city. Atlanta Journal-Constitution April 15: A1, 10.

U.S. Department of Agriculture. 1981. Land resource regions and major land resource areas of the United States. Soil Conservation Service Handbook 296. U.S. Department of Agriculture, Washington, D.C., USA.

Walters, C. 1986. Adaptive management of renewable resources. Macmillan, New York, New York, USA.
Walters, C. 1997. Challenges in adaptive management of riparian and coastal ecosystems. Conservation Ecology 1(2): 1 . URL: http://www.consecol.org/vol1/iss2/art1/index.html.

Warren, M. L., Jr., B. M. Burr, S. J. Walsh, H. L. Bart Jr., R. C. Cashner, D. A. Etnier, B. J. Freeman, B. R. Kuhajda, R. L Mayden, H. W. Robison, S. T. Ross, and W. C. Starnes. 2000. Diversity, distribution, and conservation status of the native freshwater fishes of the southern United States. Fisheries 25(10):7-29.

Wear, D. N., and J. G. Greis. 2001. The southern forest resource assessment: draft summary report. U.S. Forest Service, Asheville, North Carolina, USA.

Wiens, J. A. 1989. Spatial scaling in ecology. Functional Ecology 3:385-397.

Williams, B. K., J. D. Nichols, and M. J. Conroy. 2002. Analysis and management of animal populations. Academic Press. San Diego, California, USA.

Zhong, Y., and G. Power. 1996. Environmental impacts of hydroelectric projects on fish resources in China. Regulated Rivers: Research and Management 12:81-98. 